\title{
A CFD Modeling Method of Realistic Parameters for Predicting Easily Coal Spontaneous Combustion Zone Accurately in the Gob of Long wall Face
}

\author{
Tao Yu, Ping Lu, Junfeng Xiao \\ Department of safety engineering, Anhui Jianzhu University, Hefei 230022, Anhui, China
}

*Corresponding Author: Tao Yu, Department of safety engineering, Anhui Jianzhu University, Hefei 230022, Anhui, China

\begin{abstract}
The accurate prediction of coal spontaneous combustion zone is the precondition for the coal fire prevention. In this study, we prevent the coal spontaneous combustion on the basis of oxygen concentration and oxidation time. $10 \%$ of oxygen concentration (volume percent) is used to determine the easily coal spontaneous combustion zone and the quick advancement is used to avert the coal fire. A three-dimensional, steady flow, CFD modeling method based on realistic parameters of seepage, ventilation and working face is established and the preliminary modeling results of the spontaneous combustion zone are compared with the pipes observation for validating and amending the parameters of CFD model. The easily spontaneous combustion zones under the conditions of different air volume are quantitatively evaluated by the amended model. Simultaneously, the minimum advancing rate for averting the coal fire is determined, and the effect of accelerating advancement for the coal fire prevention is examined as well. The approach of accurate prediction is also applicable to other similar gob areas.
\end{abstract}

Keywords: coal spontaneous combustion, realistic parameters, numerical simulation, predicting model; model validation and amendment

\section{INTRODUCTION}

The spontaneous combustion of coal seams continues to be a serious problem in both underground and surface coal mining [1-3]. In China, about 10 20 million tons of coal per year are affected with \$125 250 million worth of economic damage [4]. Similar problems are faced in the United States, India, Australia, Indonesia and South Africa [5]. Coal spontaneous combustion refers to a range of complex physico-chemical processes involving consumption of oxygen, formation of solid oxygenated complexes, thermal decomposition of solid oxygenated complexes and generation of gaseous oxidation products [6]. If sufficient oxygen and conditions of heat accumulation are available, there will occur a fire. The fire induced by the coal spontaneous combustion, especially in the gob area of underground coal mining, presents accessibility problems regarding detection, fairly precise locating and fire extinguishment. If there is methane with favorable concentration, the fire can lead to a major disaster, explosion. Therefore, averting the coal fire is essential for coal mine work safety.

The accurate prediction of coal spontaneous combustion zone is the precondition for the coal fire prevention. At present, two kinds of methods are used to predict the spontaneous combustion zone. One is numerical simulation, and another is in situ observation [7]. Although in situ observation is realistic and direct, there are difficulties in comprehensively understanding the distribution for the spontaneous combustion zone in the gob area because of the accessibility problems and the severe environment. Numerical simulation provides a possibility to understand the spontaneous combustion zone due to its economic and convenient. A lot of modeling studies have been performed to investigate the spontaneous heating tendencies of coal in the gob, some models are very complicated $[8,9]$. Those help us understand the processes of coal spontaneous combustion comprehensively. However, less attention is paid to how to predict the spontaneous combustion zone accurately. Because the in situ measurements of real objects and environmental conditions are a skillful and empirical operation, and the parameters switch from real conditions to the ideal model needs a right method.

In this study, the commercial computational fluid dynamics (CFD) software, FLUENT, was used to 
predict the spontaneous combustion zone in the longwall gob area. A three-dimensional, steady flow model of the longwall district operating in the Xieqiao Coal Mine had been developed. $10 \%$ of oxygen concentration (volume percent) was the index to determine the easily coal spontaneous combustion zone. The quick advancement was the main preventive measure to avert the coal fire. The CFD modeling method based on realistic parameters of seepage, ventilation and working face was established and the preliminary modeling results of the spontaneous combustion zone were compared with the pipes observation for validating and amending the parameters of CFD model. On the base of the amended model, the easily spontaneous combustion zones under the conditions of different air volume were quantitatively evaluated. Simultaneously, the minimum advancing rate for averting the coal fire was determined, and the effect of accelerating advancement for the coal fire prevention was examined as well. The approach of accurate prediction is also applicable to other similar gob areas.

\section{NUMERICAL MODEL AND EVALUATION INDEX}

The essential conditions of coal spontaneous combustion in the gob are sufficient oxygen, favorable heat accumulation and oxidation time. Although the coal oxidation inducing self-heating is the final cause of coal spontaneous combustion, the parameters of coal oxidation reactions and heat release obtained by experimental methods exist complex scaling effects, and the heat measurement is hard to operate in the gob because of the accessibility problems and the severe environment. Therefore, in this research, we prevent the coal spontaneous combustion on the basis of oxygen concentration and oxidation time.

\subsection{Air Seepage and Oxygen Diffusion}

As the coal is extracted from the panel, the overlying coal and rock mass are caved, which forms the fractured and porous zone called gob. There may be some ventilation air leaking from the face into the gob. The mathematical model of the air leakage can be simplified as a steady flow when the ventilation is stable. The model uses equations of mass, momentum, energy and species transport [10]. In these equations, the descriptions of air seepage and oxygen diffusion is very important to simulate the distribution for oxygen concentration in the gob.

The air leaking channel of the gob is anomalistic and interlaced, which results in the very small airflow. Thus the air seepage can be treated as laminar using Darcy law:

$\bar{Q}_{x}=k_{x} \frac{\partial H}{\partial x}, \bar{Q}_{y}=k_{y} \frac{\partial H}{\partial y}, \bar{Q}_{z}=k_{z} \frac{\partial H}{\partial z}$

Where $H$ is the pressure in the gob, $\mathrm{Pa} ; \overline{Q_{x}}, \overline{Q_{y}}, \overline{Q_{z}}$ is the air velocity in $\mathrm{x}, \mathrm{y}, \mathrm{z}$ direction, $\mathrm{m} \cdot \mathrm{s}^{-1} ; k_{x}, k_{y}, k_{z}$ is the permeability in $x, y, z$ direction of the gob, $\mathrm{m}^{2}$.

The coal spontaneous combustion in the gob is a range of coal oxidation processes by the way of oxygen diffusion. The diffusion of oxygen concentration follows Fick law:

$\bar{Q}_{x} \frac{\partial C}{\partial x}+\bar{Q}_{y} \frac{\partial C}{\partial y}+\bar{Q}_{z} \frac{\partial C}{\partial z}=D_{x} \frac{\partial^{2} C}{\partial x^{2}}+D_{y} \frac{\partial^{2} C}{\partial y^{2}}+D_{z} \frac{\partial^{2} C}{\partial z^{2}}$

Where $D_{x}, D_{y}, D_{z}$ is the diffusion coefficient of oxygen in $x, y, z$ direction of the coal bodies, $\mathrm{m}^{2} \cdot \mathrm{s}^{-1}, C$ is the oxygen concentration, $\mathrm{mol} \cdot \mathrm{m}^{-3}$.

\subsection{Definition of Easily Spontaneous Combustion Zone}

The air seepage and oxygen diffusion lead to the distribution of oxygen concentration in the gob, which influences coal oxidation processes. The distribution for oxygen concentration determines the coal spontaneous combustion zone. Some researches show that the coal oxidation is restricted when the oxygen concentration less than $10 \%$ and even suppressed when less than $5 \%$ [11]. Thus $10 \%$ of oxygen concentration can be the index to determine the coal spontaneous combustion zone. The zone that oxygen concentration is greater than $10 \%$ in the gob is easily spontaneous combustion zone.

\subsection{Oxidation Time and Advancement}

It is quite obvious that coal spontaneous combustion would happen where meets enough oxidation time. That is to say:

$t>t_{\min }$ 
A CFD Modeling Method of Realistic Parameters for Predicting Easily Coal Spontaneous Combustion Zone Accurately in the Gob of Long wall Face

Where $t$ is the oxidation time, $\mathrm{d}$, and $t_{\min }$ is the minimum period of coal spontaneous combustion, $\mathrm{d}$, which is obtained by the larger scale experiment or field statistics.

However with the face advancing, the contour line of oxygen concentration $10 \%$ follows, which leads to dynamically changes of the easily spontaneous combustion zone in the gob. If the face advancing velocity $(V)$ follows the Eq. (4), the coal spontaneous combustion would not happen.

$V>\left[V_{\min }=D_{\max } / t_{\min }\right]$

Where $D_{\max }$ is the largest distance from the face to the contour line of oxygen concentration $10 \%$, m, $V_{\min }$ is the minimum advancing velocity to advert coal spontaneous combustion, $\mathrm{m} \cdot \mathrm{d}^{-1}$.

\section{Modeling Method of Realistic Parameters}

\subsection{Parameters of Seepage}

The porosity of the gob varied with the location of the site. It is largest around the perimeter of the gob and immediately behind the face shields. The value in the vertical direction decreases with power function. The porosity followed the equation ascertained by field simulation experiment[12]:

$\varphi(x, y, z)=\left(0.2 e^{-0.022 x}+0.1\right) \times\left[e^{-0.12\left(\frac{L^{ \pm}}{2}\right)}+1\right] \times 0.98^{z}$

Where $\varphi$ is the porosity of the gob; $x$ is the depth of the gob, m, $y$ is the distance from the site to the middle line of the gob, $\mathrm{m}, z$ is the height of the gob, $\mathrm{m}, L$ is the length of the longwall face, $\mathrm{m}$.

Using the values of porosity, an exponential relationship was used to compute the permeability of the gob as follows[12]:

$k=k_{0} \mathrm{e}^{\beta \varphi}$

Where $k_{o}$ is the base permeability of the gob at the maximum porosity, $\mathrm{m}^{2}$, and $\beta$ is the empirical coefficient. The value of $k_{o}$ was taken as $2 \times 10^{-5} \mathrm{~m}^{2}$ which occurred behind the face shields[13], and the value of $\beta$ is determined by the in situ observation amending simulated results. The triaxial permeability experiment show that the value of $\beta$ is about 10 30 under the conditions of confining pressure $6 \mathrm{MPa}$, pore pressure $0.6 \mathrm{MPa}$ and temperature $293 \mathrm{~K}[14]$.

Taking the example of 13413 panel of Xieqiao coal mine, the length of the longwall face is $206 \mathrm{~m}$. The values of the porosity in the gob can be calculated by the Eq. (5), and the 3D distribution for the porosity is displayed in Fig. 1

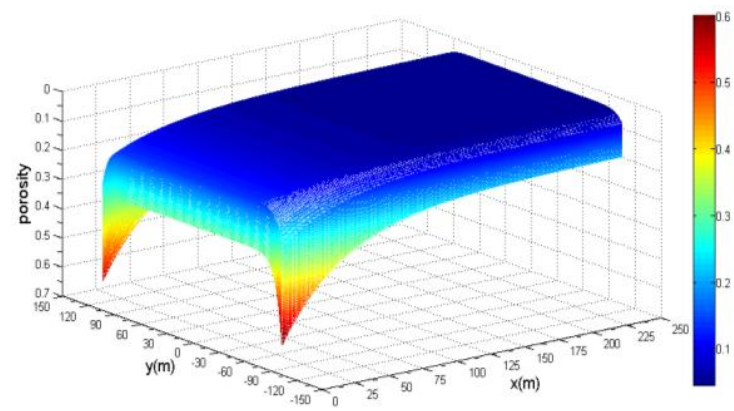

Fig1. The 3D distribution for the porosity in the gob

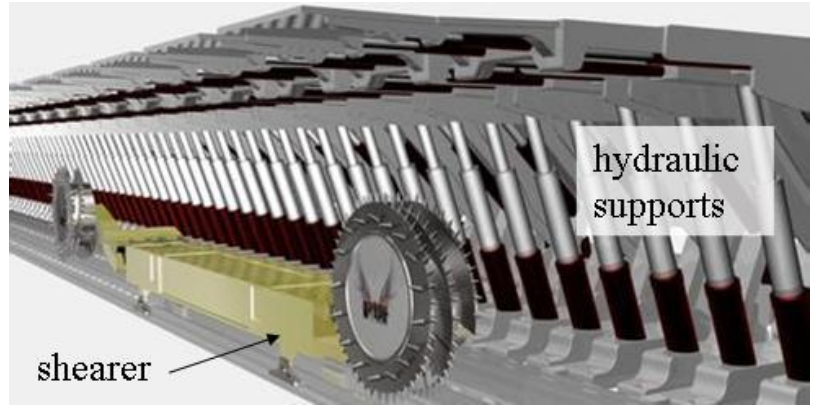

Fig2. The structure of long wall face

\subsection{Parameters of Ventilation}

When air is moving in the roadways, the airflow is influenced by the friction resistance, especially in the longwall face, which include a mechanical shearer and hydraulic supports as shown in Fig. 2. The influence of the friction resistance can be reflected by pressure distribution. According to the Bernoulli's equation, the pressure difference between two points, $P_{R l, 2}$, equal the ventilating resistance, which can be calculated as follows:

$P_{R 1,2}=P_{b 1}-P_{b 2}+\left(P_{a 2}-P_{a 1}\right)+\frac{1}{2} \rho_{1} v_{1}^{2}-\frac{1}{2} \rho_{2} v_{2}^{2}+g \rho_{m, 2} z_{1,2}$

Where $P_{a i}$ is relative static pressure on the base point when the test point $i$ is measuring, $\mathrm{Pa}$ 
A CFD Modeling Method of Realistic Parameters for Predicting Easily Coal Spontaneous Combustion Zone Accurately in the Gob of Long wall Face

$P_{b i}$ is relative static pressure of the test point $i, \mathrm{~Pa}$

$\rho_{i}$ is air density of the test point $i, \mathrm{~kg} \cdot \mathrm{m}^{-3}$

$v_{i}$ is air speed of the test point $i, \mathrm{~m} \cdot \mathrm{s}^{-1}$

$g$ is acceleration of gravity, $\mathrm{m} \cdot \mathrm{s}^{-2}$

$\rho_{m}$ is average density of the air between two test points, $\mathrm{kg} \cdot \mathrm{m}^{-3}$

$Z_{i, i+1}$ is elevation difference between test point $i$ and $i+1, \mathrm{~m}$

The air density can be calculated as the following equation[15]:

$\rho_{i}=3.484 \frac{P}{T}\left(1-\frac{0.378 \lambda P_{\text {sat }}}{P}\right)$

Where $P$ is absolute atmospheric pressure, $\mathrm{KPa}, T$ is absolute air temperature, $\mathrm{K}, \lambda$ is relative air humidity, $\%$, and $P_{\text {sat }}$ is saturation vapor pressure, $\mathrm{KPa}$.

The airflow resistance coefficient, $R_{12}, \mathrm{Ns}^{2} \cdot \mathrm{m}^{-8}$, can be written as[15]:

$R_{12}=\frac{P_{R 12}}{Q^{2}}$

Where $Q$ is air volume of roadway, $\mathrm{m}^{3} \cdot \mathrm{s}^{-1}$. The airflow resistance coefficient is the intrinsic attribute of the roadways, which does not vary with the air volume variation. Thus the pressure difference of roadways with different air volume can be calculated by the Eq. (9).

The test instruments are the precision digital barometer, wet and dry bulb thermometer and mechanical anemometer of high, medium and low speed as shown in Fig. 3. The precision of the precision digital barometer is 0.1 and the precision of the wet and dry bulb thermometer is 0.5 .

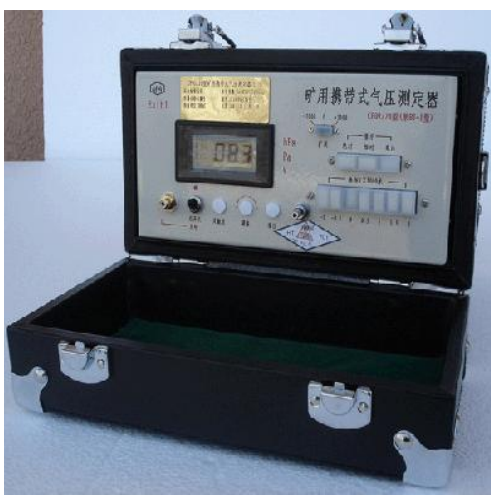

(a) the precision digital barometer

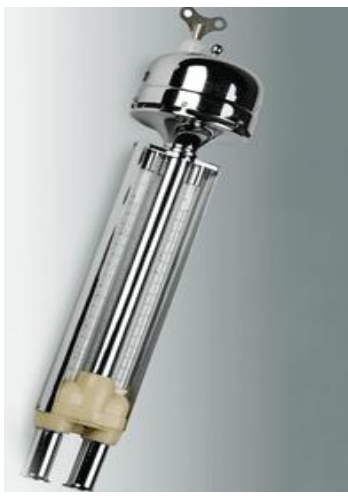

(b) the wet and dry bulb thermometer

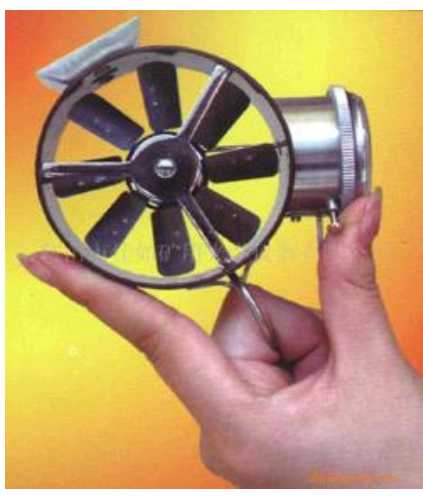

(c) the mechanical anemometer

Fig3. The instruments for air resistance test

\subsection{Modeling Parameters of the Working Face}

During mining of a panel, roof rocks are temporarily supported with hydraulic supports to protect the workers and the equipment. The supports automatically advance and the gob are formed behind. The backplate of each hydraulic support is used to prevent caved rocks from rolling in the workplace. As shown in Fig. 4, the edge interval of each backplate is about $80 \mathrm{~mm}$ and the middle interval of each hydraulic support is about $1.5 \mathrm{~m}$, which are set as rectangular walls. These realistic parameters are used for modeling.

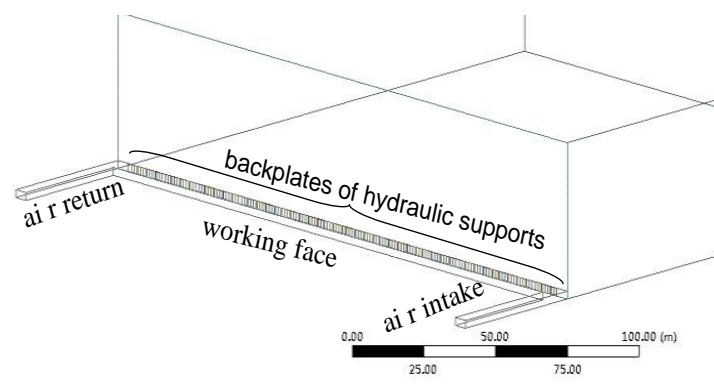

Fig4.The model parameters for backplates of hydraulic supports

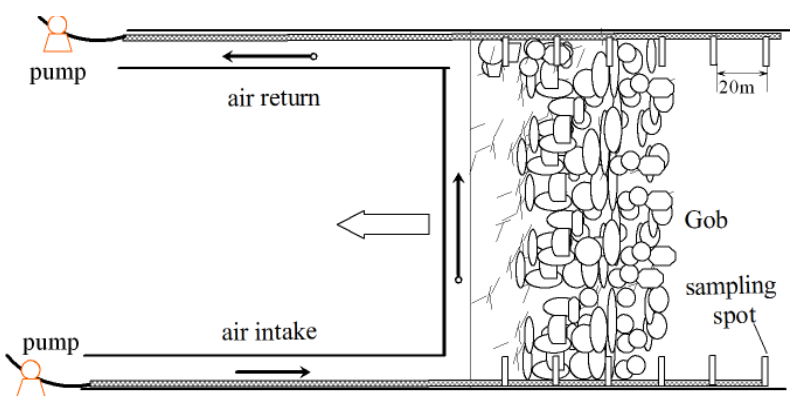

Fig5. The arrangement for sampling observation in the gob 
A CFD Modeling Method of Realistic Parameters for Predicting Easily Coal Spontaneous Combustion Zone Accurately in the Gob of Long wall Face

\subsection{Method of Validation and Amendment}

Due to the complex mining environment, the simulated results are prone to error. Therefore, the validation and amendment of modeling parameters are quite essential. The in situ measuring method of pipes observation is available for validation and amendment. Basically, the pipes are buried in the roadways beforehand and the air samples are taken from pumping the pipes. Multiple sampling spots are arranged for accurate testing, which interval is $20 \mathrm{~m}$. The oxygen concentration is tested by the chromatography as the working face advancement leading to the pre-buried pipes going into the gob, as shown in Fig. 5. The different oxygen concentration of different sites are obtained for validation and amendment by comparing with simulated results consequently. The empirical coefficient $\beta$ of Eq.(6) is amended as well.

\section{Predicting Easily Coal Spontaneous Combustion Zone}

\subsection{Parameters of the Model}

The 13413 panel of longwall face situated at the Xieqiao mine of Huainan city operated with the caving method of retreat mining. The length of the face is $206 \mathrm{~m}$, the mining height of the face was 4 $\mathrm{m}$, and the gob height was assumed to be ten times larger than the mining height, i.e. $40 \mathrm{~m}$ starting from the bottom of the coal seam. The calculated length of air intake and return is $50 \mathrm{~m}$. A back return U-ventilation system was used with an airflow rate of $2500 \mathrm{~m}^{3} \cdot \mathrm{min}^{-1}$ in the intake. The ventilation roadways are $3 \mathrm{~m}$ high and $5 \mathrm{~m}$ wide. The calculated depth of the gob is $250 \mathrm{~m}$. The model is sketched in Fig. 6.

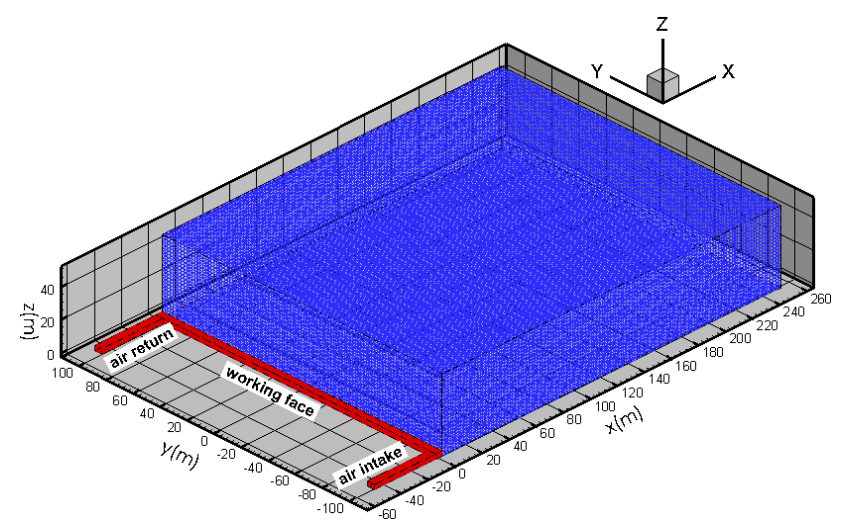

Fig6. The 3D model and grid cells of the longwall district

\subsection{Basic Approach to Numerical Modeling}

A three-dimensional, steady flow numerical model of the longwall district has been developed with the commercial CFD software program FLUENT (Ansys, Inc.), version 14.0. The cells grid for the simulation is created using mesh generator of Workbench (Ansys, Inc.). The cells of the gob are the shape of regular hexahedrons with a side length of $2 \mathrm{~m}$. The grid cells are sketched in Fig. 6.

The airflow at the longwall face and roadways is simulated as fully developed turbulent flow using an RNG $\mathrm{k}-\varepsilon$ model. The inlet of the air intake is set as velocity inlet and the outlet of the air return is set as pressure outlet. The pressure difference between the inlet and outlet was $162.1 \mathrm{~Pa}$ by the in situ measurement with air volume $2500 \mathrm{~m}^{3} / \mathrm{min}$. Thus the airflow resistance coefficient is $0.093 \mathrm{Ns}^{2} \cdot \mathrm{m}^{-8}$ according to the Eq. (9). The pressure difference between the inlet and outlet with air volume $2000 \mathrm{~m}^{3} / \mathrm{min}$ and $3000 \mathrm{~m}^{3} / \mathrm{min}$ are calculated as well, which are $103.7 \mathrm{~Pa}$ and $233.3 \mathrm{~Pa}$ respectively.

Using the model, the air velocity and oxygen concentration in the gob area can be simulated from the starting line of the longwall face up to the $250 \mathrm{~m}$ depth of the gob.

\subsection{Model Validation and Amendment}

As shown in Fig. 7, The drop curves of the oxygen concentration at both sides of the gob are obtained by the pipes observation. At $124 \mathrm{~m}$ and $88 \mathrm{~m}$ from the working face, the oxygen concentration reaches $10 \%$, and at $60 \mathrm{~m}$ and $25 \mathrm{~m}$ from the working face, the oxygen concentration reaches $18 \%$. The value of the empirical coefficient $\beta$ of Eq.(6) is 19.5 by repeated simulation so that simulated results meet the in situ observation. 
A CFD Modeling Method of Realistic Parameters for Predicting Easily Coal Spontaneous Combustion Zone Accurately in the Gob of Long wall Face

As shown in Fig. 7, the distribution for the oxygen concentration field at gob bottom was obtained through simulations with air volume of $2500 \mathrm{~m}^{3} / \mathrm{min}$. At the gob bottom, the contour line of $10 \%$ reaches the distance of $130 \mathrm{~m}$ and $90 \mathrm{~m}$ from the working face at both sides respectively. The contour line of $18 \%$ reaches the distance of $59 \mathrm{~m}$ and $15 \mathrm{~m}$ from the working face at both sides respectively.

The numerical simulation results are in good agreement with the in situ observation, validating the accuracy of numerical model. Therefore, the settings of the real parameters can be a basis of subsequent modeling.

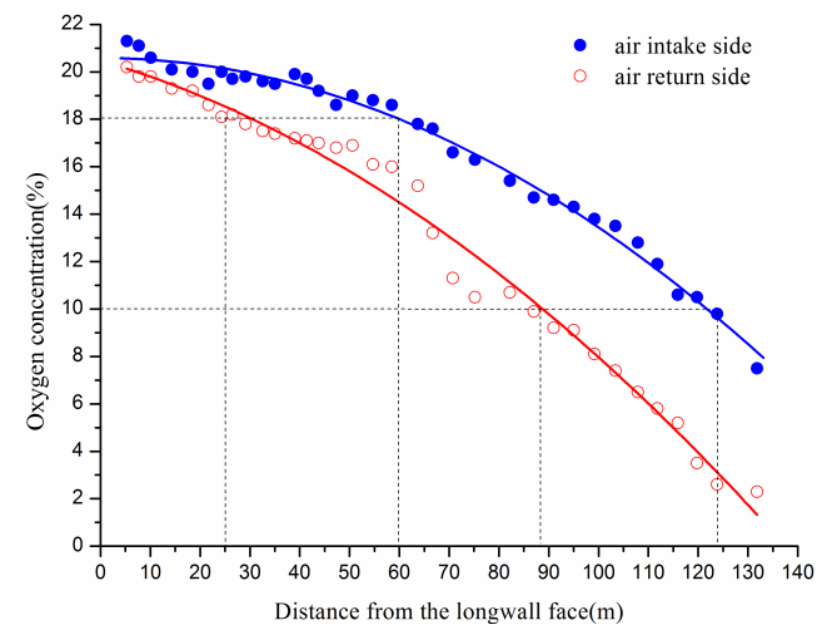

Fig7. The pipes observation results in both sides of the gob

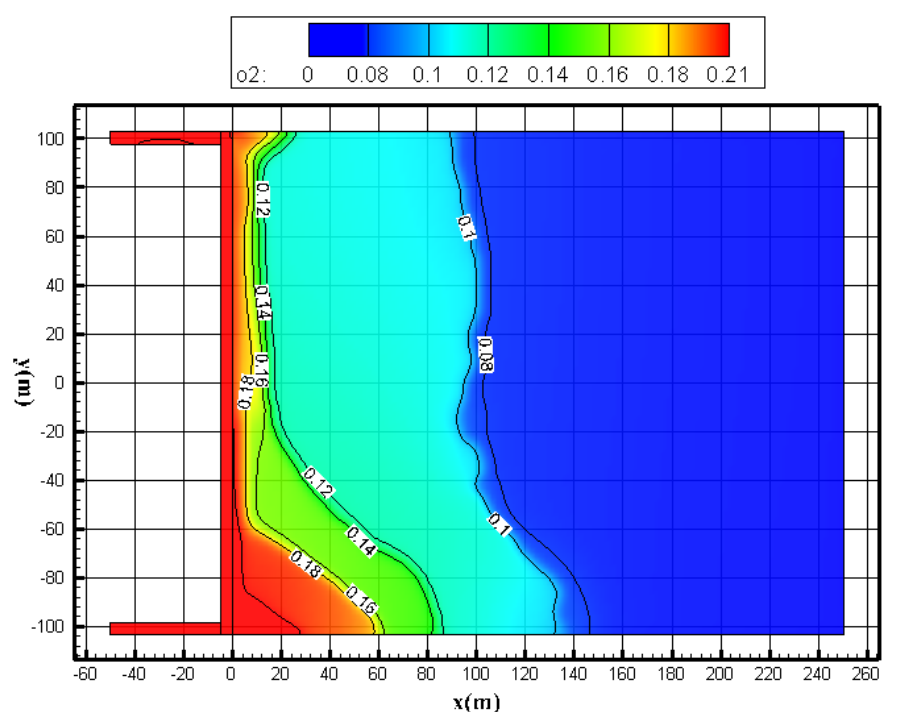

Fig8. The oxygen concentration field at the gob bottom $\left(2500 \mathrm{~m}^{3} / \mathrm{min}\right)$

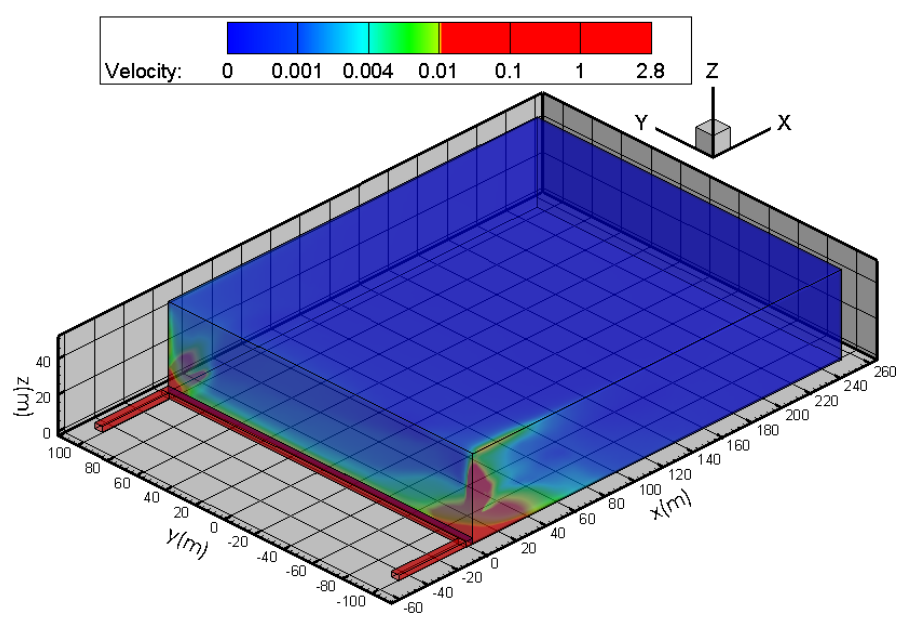

Fig9. The $3 D$ air velocity field in the gob $\left(2500 \mathrm{~m}^{3} / \mathrm{min}\right)$ 


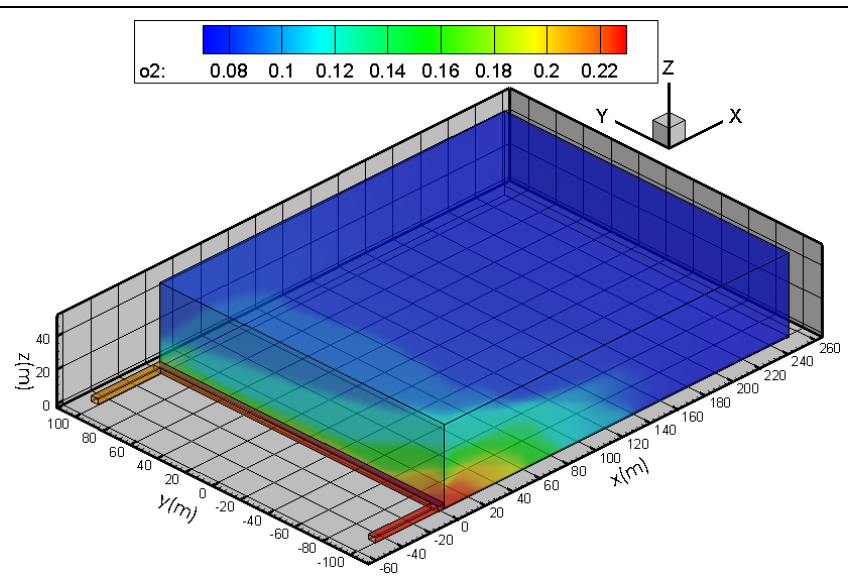

Fig10. The $3 D$ oxygen concentration field in the $\operatorname{gob}\left(2500 \mathrm{~m}^{3} / \mathrm{min}\right)$

\subsection{Spatial Distribution of the Spontaneous Combustion Zone}

Fig. 9. and Fig. 10. illustrate the distribution for the air velocity field and oxygen concentration field in the three-dimensional space. The air leakage is mainly concentrated at intake and return sides of the gob, and the air leakage of the intake side is larger than the middle and return side of the gob, resulting in the wider spontaneous combustion zone at the air intake of the gob. The distribution for easily spontaneous combustion zone is gradually decreased from the bottom to the top of the gob because of the decreases of permeability in the vertical direction. Thus the spontaneous combustion zone of the gob bottom is the widest zone, which is very significant for coal fire prevention.

\subsection{Influence of Air Volume}

In order to understand the influence of different air volume for easily spontaneous combustion zone, the oxygen concentration fields at gob bottom were obtained by simulations with air volume of $2000 \mathrm{~m}^{3} / \mathrm{min}$ and $3000 \mathrm{~m}^{3} / \mathrm{min}$, see Fig. 11. and Fig. 12. The modeling parameters were based on the validated model. Table 1 shows the range of the easily spontaneous combustion zone at the air intake, return side and middle of the gob bottom. The easily spontaneous combustion zone of the air intake, return side and middle decrease by $20 \mathrm{~m}, 33 \mathrm{~m}$ and $5 \mathrm{~m}$ respectively when the air volume decreases by $500 \mathrm{~m}^{3} / \mathrm{min}$. The easily spontaneous combustion zone of the air intake, return side and middle increase by $20 \mathrm{~m}, 0 \mathrm{~m}$ and $15 \mathrm{~m}$ respectively when the air volume increases by $500 \mathrm{~m}^{3} / \mathrm{min}$. The results indicate that the easily spontaneous combustion zone of the air intake side increases significantly and the air return side increases slowly with the air volume increase, namely, the spontaneous combustion risk of the air intake side is greatest in the gob. Thus the distance of the easily spontaneous combustion zone at air intake of the gob bottom can be the basis for calculating the minimum advancing velocity to advert coal spontaneous combustion.

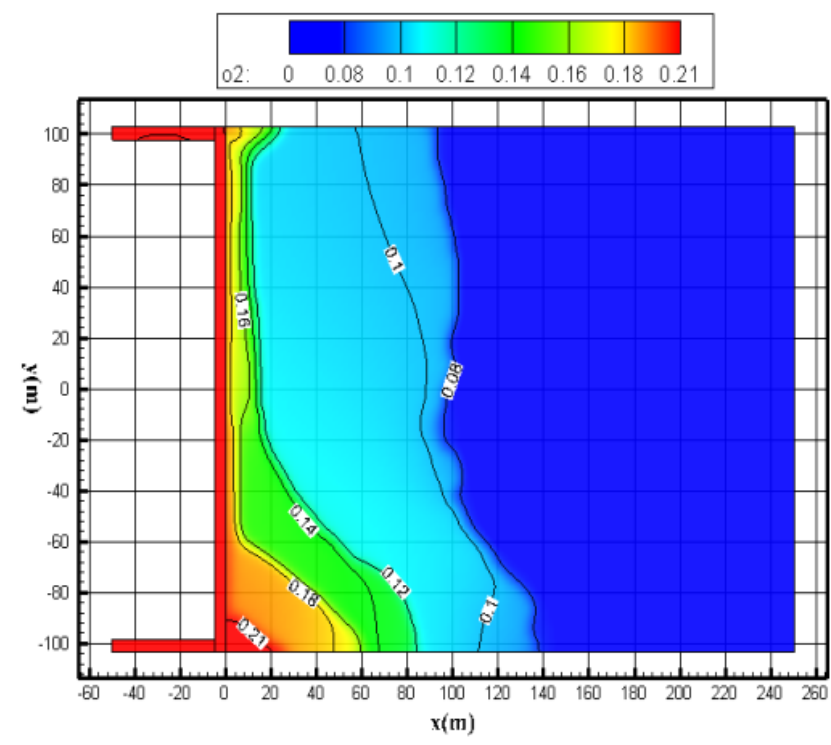

Fig11. The oxygen concentration field at the gob bottom $\left(2000 \mathrm{~m}^{3} / \mathrm{min}\right)$ 


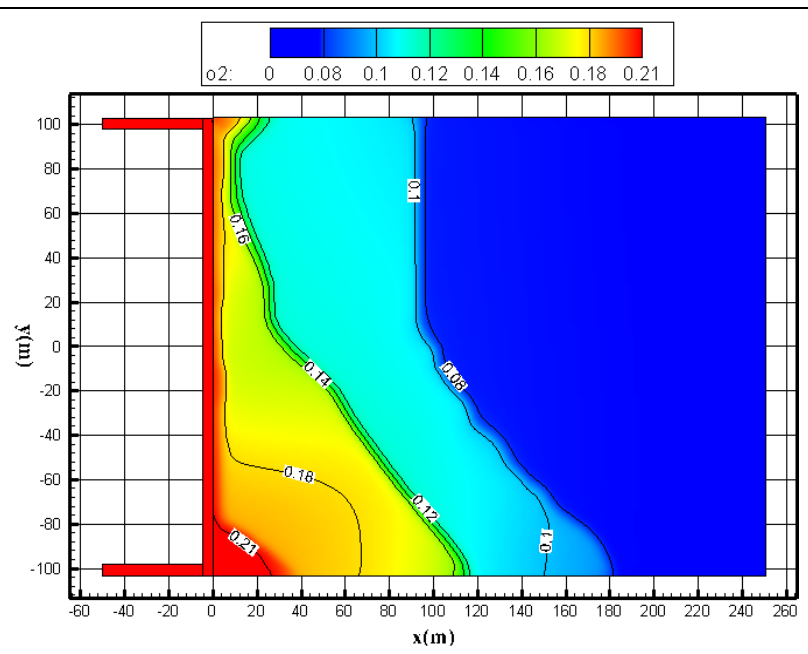

Fig12. The oxygen concentration field at the gob bottom $\left(3000 \mathrm{~m}^{3} / \mathrm{min}\right)$

Table1. The distribution for easily spontaneous combustion zone

\begin{tabular}{|c|c|c|c|}
\hline \multirow{2}{*}{$\begin{array}{c}\text { Air volume } \\
\left(\mathrm{m}^{3} / \mathrm{min}\right)\end{array}$} & \multicolumn{3}{|c|}{ The length of easily spontaneous combustion zone $(\mathrm{m})$} \\
\hline & Air intake side & Air return side & Middle \\
\hline 2000 & 110 & 57 & 90 \\
\hline 2500 & 130 & 90 & 95 \\
\hline 3000 & 150 & 90 & 110 \\
\hline
\end{tabular}

\subsection{Effect of Preventing Spontaneous Combustion}

The minimum spontaneous combustion period of the 13-1 coal seam of 13413 panel is $39 \mathrm{~d}$. According the present simulations and Eq.(4), the minimum advancing velocity of the working face must be faster than $85 \mathrm{~m}, 100 \mathrm{~m}$ and $116 \mathrm{~m}$ per month with air volume of $2000 \mathrm{~m}^{3} / \mathrm{min}, 2500 \mathrm{~m}^{3} / \mathrm{min}$ and $3000 \mathrm{~m}^{3} / \mathrm{min}$. During the 13413 panel mining, the average air volume was $2500 \mathrm{~m}^{3} / \mathrm{min}$ and the maximum air volume reached $3000 \mathrm{~m}^{3} / \mathrm{min}$ for controlling methane emission. The average advancing velocity was $120.9 \mathrm{~m}$ per month and carbon monoxide was not detected in the air return. Thus the coal spontaneous combustion in the gob is successfully suppressed by accelerating advancement.

\section{CONCLusions}

In this study, the CFD modeling based on the realistic parameters of seepage, ventilation and working face is used to predict spontaneous combustion zone. The results demonstrate that the numerical simulation is in good agreement with the in situ observation, validating the accuracy of numerical model. Then, the easily spontaneous combustion zones under the conditions of different air volume are quantitatively evaluated by the accuracy model. The results show that the spontaneous combustion zone at the air intake side of the gob bottom is the widest zone. The easily spontaneous combustion zone of the air intake side increases significantly and the air return side increases slowly with the air volume increase, namely, the spontaneous combustion risk of the air intake side is greatest in the gob. Finally, based the results, the minimum advancing velocity is calculated to advert coal spontaneous combustion, which proves that the coal spontaneous combustion in the gob is successfully suppressed by accelerating advancement.

\section{ACKNOWLEDGEMENTS}

This work was supported by Natural Science Research Project of Anhui Education Department (No. KJ2016JD02). The authors deeply appreciate their support.

\section{REFERENCES}

[1] Wessling S, Kuenzer C, Kessels W, Wuttke WM. Numerical modeling for analyzing thermal surface anomalies induced by underground coal fires. Int J Coal Geol 2008;74:175-84.

[2] Yuan L, Smith AC. Effect of longwall face advance on spontaneous heating in longwall gob area. Mining Eng; March 2010.

[3] Wolf $\mathrm{KH}$, Bruining $\mathrm{H}$. Modelling the interaction between underground coal fires and their roof rocks. Fuel 2007;86:2761-77. 
A CFD Modeling Method of Realistic Parameters for Predicting Easily Coal Spontaneous Combustion Zone Accurately in the Gob of Long wall Face

[4] Liu L, Zhou FB. A comprehensive hazard evaluation system for spontaneous combustion of coal in underground mining. Int J Coal Geol 2010;82:27-36.

[5] DeRosa M. Analysis of mine fires for all US underground and surface coal mining categories, 1990-1999. National Institute for Occupational Safety and Health Information Circular 9470; 2004.

[6] Wang H, Dlugogorski BZ, Kennedy EM. Progr Energy Combust Sci 2003;29:487-513.

[7] Carras JN, Young BC. Self-heating of coal and related materials: models, application and test methods. Prog Energ Combust Sci 1994;20:1-15.

[8] Fierro V, Miranda J L, Romero C, et al. Model predictions and experimental results on self-heating prevention of stockpiled coals. Fuel, 2001(80): 125-134

[9] Sahu HB, Padhee S, Mahapatra SS. Prediction of spontaneous heating susceptibility of Indian coals using fuzzy logic and artificial neural network models. Expert Syst Appl 2011;38:2271-82.

[10] Yuan L, Smith AC. CFD modeling of spontaneous heating in a large-scale coal chamber. J Loss Prevent Proc 2009;25:426-33.

[11] Rosema A, Guan H, Veld H. Simulation of spontaneous combustion, to study the causes of coal fires in the Rujigou Basin. Fuel 2001;80:7-16.

[12] Liu J, Chen Z, Elsworth D, Qu H, Chen D. Interactions of multiple processes during CBM extraction: a critical review. Int J Coal Geol 2011;87:175-89.

[13] Wang J, Kabir A, Liu J, Chen Z. Effects of non-Darcy flow on the performance of coal seam gas wells. Int J Coal Geol 2012;93:62-74.

[14] Detournay E, Cheng AHD. Fundamentals of poroelasticity. In: Fairhurst C, editor. Compr rock eng, vol. 2. Oxford: Pergamon; 1993. p. 113-71.

[15] Yu, Tao, et al. "Optimization of Ventilating Energy Distribution for Controlling Coal Spontaneous Combustion of Sealed Panel in Underground Coal Mines." Procedia Engineering 62 (2013): 972-979

Citation: Tao Yu et al. (2017). A CFD Modeling Method of Realistic Parameters for Predicting Easily Coal Spontaneous Combustion Zone Accurately in the Gob of Long wall Face, International Journal of Mining Science (IJMS), 3(2), pp.40-48, DOI: http://dx.doi.org/ 10.20431/2454-9460.0302004.

Copyright: (C) 2017 Tao Yu. This is an open-access article distributed under the terms of the Creative Commons Attribution License, which permits unrestricted use, distribution, and reproduction in any medium, provided the original author and source are credited 